\title{
LA REFORMA ELECTORAL OAXAQUEÑA EN LOS AYUNTAMIENTOS MIXES
}

\author{
Teresa Valdivia Dounce \\ teresavd@yahoo.com \\ INSTITUTO DE INVESTIGACIONES ANTROPOLÓGICAS \\ UNIVERSIDAD NACIONAL AUTÓNOMA DE MÉXICO
}

\begin{abstract}
RESUMEN
Se revisan los posibles efectos de las reformas en materia electoral indígena en los municipios de la región mixe de Oaxaca, comparando las tendencias políticas anteriores a las reformas, observadas en investigación de campo, con los resultados de las elecciones federales de 2006 y estatales de 2007.
\end{abstract}

Palabras clave: Reforma electoral, elecciones por usos y costumbres.

\begin{abstract}
This paper reviews the possible effects of indigenous electoral reforms in the municipalities in the Oaxacan Mixe region, comparing political tendencies prior to reforms, as observed in field research, with results from federal elections in 2006 and state elections in 2007.
\end{abstract}

Key words: Electoral reform, elections according to traditions. 
Con una serie de reformas que tuvieron lugar en el estado de Oaxaca, durante el periodo 1995 a 2008, se reconoció que las comunidades indígenas pueden elegir a sus autoridades de acuerdo con su costumbre. Desde que se hicieron estas reformas no han sido evaluados los efectos políticos que generaron en los municipios oaxaqueños. Por lo tanto, intentaré identificar algunas de sus consecuencias, partiendo de la investigación que realicé en los 19 municipios de la región mixe. ${ }^{1}$

Las reformas son las siguientes: en 1995 se modificó el artículo 25 de la Constitución Política del Estado Libre y Soberano de Oaxaca, el cual señala en su Fracción II que «la ley protegerá y propiciará las prácticas democráticas en todas las comunidades del estado de Oaxaca, para la elección de los ayuntamientos». También se reformó el artículo 28 de la Ley Municipal para el Estado de Oaxaca, el 10 de enero de 2003, para establecer que «las elecciones municipales tendrán lugar en la fecha que determine el Código de Instituciones Políticas y Procedimientos Electorales de Oaxaca, en las que se respetarán las tradiciones, usos, costumbres y prácticas democráticas de las comunidades». Y, en el artículo 23 de la misma ley, se precisó que «los Concejales electos por el sistema de usos y costumbres tomarán posesión en la misma fecha y desempeñarán el cargo durante el tiempo que sus tradiciones y prácticas democráticas determinen, pero no podrá exceder de tres años».

Asimismo, el Código de Instituciones Políticas y Procedimientos Electorales de Oaxaca fue reformado el 30 de agosto de 1995 y, posteriormente, el 30 de septiembre de 1997, en sus artículos 71, 73, 78, 79, 110, 114, 120, 121, 122; con el fin de establecer los procedimientos para la votación mediante usos y costumbres. Once años después, este código sufrió nuevas modificaciones, que fueron publicadas el 8 de noviembre del año 2008; con ellas se reconoció en sus artículos 131 a 143 el sistema electoral consuetudinario.

Por su parte, la Ley de Derechos de los Pueblos y Comunidades Indígenas del Estado de Oaxaca — decretada el 16 de junio de 1998 - no establece expresamente ninguna norma en materia electoral, aunque hace referencia a la autonomía de los núcleos de población organizados como agencias o municipios, o conjuntos de ellos -artículos 8 y 10-, lo cual implica la existencia de una forma de representación política. La misma ley también reconoce en lo general los sistemas normativos de los pueblos y comunidades 
indígenas, dentro de los cuales debe comprenderse al sistema electoral -artículos 28 y 29-, aunque no lo dicte expresamente, pues el sentido de la mayoría de los artículos referentes a los sistemas normativos se dirige a los sistemas de justicia penal y civil.

\section{II}

Ante todo es necesario considerar que previo a las citadas reformas en materia electoral en el estado de Oaxaca se sostuvieron tres tendencias políticas: 1) dar preferentemente los votos al PRI para la renovación de los ayuntamientos, las diputaciones, senadurías y presidencia de la República; 2) elegir a las autoridades locales, en la mayoría de los casos, conforme a su costumbre - aproximadamente, 70\% de los municipios-; y 3) «negociar» los pueblos y comunidades indígenas, especialmente los caciques locales, con el gobierno estatal y con el PRI el voto a este partido, a cambio de la sobrevivencia de su costumbre y autonomía electoral para la renovación de sus ayuntamientos.

A estas prácticas también han sido fieles los pueblos mixes. Pero, cabe preguntarse ahora, desde que se reconocieron los usos y costumbres electorales isiguen practicándose estas tendencias? Para intentar responder, iré por partes.

En Oaxaca hay 25 distritos electorales, de los cuales solamente en dos votan 100\% con la modalidad de usos y costumbres: en el Distrito III de Ixtlán de Juárez y en el XX de San Pedro y San Pablo Ayutla, aunque en general en dos terceras partes de los municipios del Estado se mantiene el voto de acuerdo con la costumbre desde que esta modalidad fue reconocida. En el caso de los municipios mixes, todos corresponden al Distrito XX de San Pedro y San Pablo Ayutla, excepto San Juan Juquila Mixes, que pertenece al Distrito Electoral IV de Tlacolula de Matamoros, y San Juan Guichicovi que pertenece al Distrito Electoral XXIV de Matías Romero. Todos se registraron para votar por usos y costumbres en las votaciones de 1995, 1998, 2001, 2004 y 2007, excepto Guichicovi, que en las votaciones de 2004 para concejales de ayuntamientos optó votar por partidos políticos, resultando ganador PRD y como segunda fuerza PRI (IFE 2006).

Entonces, ¿se puede decir que el registro del voto por usos y costumbres ha desplazado al de partidos en la región mixe? Yo creo que sí, en lo general, pero hay que considerar varios asuntos. El primero de ellos es que el registro del voto por usos y costumbres no ha sido realmente una adopción. Los pueblos mixes han practicado este tipo 
de elecciones durante muchos años; por lo menos desde antes de que existieran los partidos políticos. Así que más que una adopción para los pueblos mixes el voto por usos y costumbres es un reconocimiento a su práctica histórica y tradicional.

Aunque es necesario decir que, para algunos, este reconocimiento no fue un acto de «buena voluntad» sino una estrategia más del partido PRI para ganar legitimidad y preservar la gobernabilidad en Oaxaca (Anaya s/f, Recondo 1999).

El segundo aspecto que hay que tomar en cuenta es que la reforma que ha permitido este tipo de voto se refiere exclusivamente a la renovación de los ayuntamientos y no a la elección de diputados, senadores y presidente de la República, lo cual es consecuente con la aceptación y validación de la tendencia comunitaria; pero hay que subrayar aquí que deja libre la acción de los partidos en el ámbito local para todas las demás elecciones, y en ésas la preferencia de los pueblos mixes sigue siendo el PRI, aunque en algunos casos con mucha competencia por parte del PRD. Por lo menos esa fue la tendencia observada en las elecciones federales del año 2006 y en las estatales de 2007 (tablas 1, 2, 3, 4, 5). 
TABLA 1. PORCENTAJE DE VOTOS EN LAS ELECCIONES FEDERALES PARA DIPUTADOS, 2006,

REGIÓN MIXE, OAXACA

\begin{tabular}{|c|c|c|c|c|c|c|}
\hline Nombre del municipio & $P A N$ & $P R I$ & $P R D$ & Otros & No registrados & Nulos \\
\hline Asunción Cacalotepec & 10.33 & 43.28 & 37.38 & 2.79 & 0.33 & 5.90 \\
\hline Mixistlán de la Reforma & 5.79 & 67.51 & 21.07 & 0.75 & 0.45 & 4.45 \\
\hline San Juan Cotzocón & 14.23 & 42.67 & 36.89 & 2.37 & 0.29 & 3.56 \\
\hline San Juan Guichicovi & 3.14 & 44.94 & 48.73 & 0.89 & 0.11 & 2.18 \\
\hline San Juan Juquila Mixes & 22.29 & 26.27 & 36.36 & 2.78 & 0.65 & 11.66 \\
\hline San Juan Mazatlán & 12.92 & 51.23 & 27.51 & 2.07 & 0.52 & 5.76 \\
\hline San Lucas Camotlán & 39.02 & 39.02 & 14.29 & 1.05 & 0.00 & 6.62 \\
\hline San Miguel Quetzaltepec & 5.75 & 49.64 & 34.64 & 1.20 & 0.08 & 8.70 \\
\hline San Pedro Ocotepec & 13.15 & 61.79 & 20.10 & 2.73 & 0.00 & 2.23 \\
\hline San Pedro y San Pablo Ayutla & 16.30 & 39.47 & 31.65 & 2.41 & 0.66 & 9.50 \\
\hline Santa María Alotepec & 8.05 & 23.90 & 56.75 & 1.56 & 2.21 & 7.53 \\
\hline Santa María Tepantlali & 14.62 & 44.71 & 25.04 & 2.52 & 3.86 & 9.24 \\
\hline Santa María Tlahuitoltepec & 17.63 & 13.87 & 51.98 & 8.42 & 1.04 & 7.06 \\
\hline Santiago Atitlán & 14.01 & 33.41 & 42.24 & 1.51 & 1.08 & 7.76 \\
\hline Santiago Ixcuintepec & 15.01 & 62.47 & 14.79 & 0.66 & 0.00 & 7.06 \\
\hline Santiago Zacatepec & 20.03 & 31.75 & 34.47 & 2.54 & 0.76 & 10.44 \\
\hline Santo Domingo Tepuxtepec & 15.85 & 53.09 & 19.76 & 3.23 & 1.41 & 6.73 \\
\hline Tamazulapam del Espíritu Santo & 14.20 & 15.93 & 59.72 & 4.31 & 0.73 & 5.11 \\
\hline Totontepec Villa de Morelos & 26.43 & 37.64 & 27.66 & 2.29 & 0.25 & 5.73 \\
\hline Porcentaje total en la región & 15.19 & 41.18 & 33.73 & 2.42 & 0.75 & 6.69 \\
\hline
\end{tabular}

Fuente: Instituto Federal Electoral, en http://pac.ife.org.mx

Nota: Los datos de esta tabla se refieren solamente a los votos emitidos, los cuales representan casi $40 \%$ de la lista nominal. Tampoco se tomaron en cuenta las casillas especiales. 
TABLA 2. PorCENTAJE DE VOTOS EN LAS ELECCIONES FEDERALES PARA SENADORES, 2006, REGIÓN MIXE, OAXACA

\begin{tabular}{|c|c|c|c|c|c|c|}
\hline Nombre del municipio & $P A N$ & PRI & $P R D$ & Otros & No registrados & Nulos \\
\hline Asunción Cacalotepec & 9.18 & 42.13 & 40.66 & 2.13 & 0.66 & 5.25 \\
\hline Mixistlán de la Reforma & 6.09 & 67.16 & 20.51 & 1.48 & 0.30 & 4.46 \\
\hline San Juan Cotzocón & 14.45 & 41.50 & 38.16 & 1.64 & 0.29 & 3.96 \\
\hline San Juan Guichicovi & 2.70 & 44.90 & 49.66 & 0.64 & 0.13 & 1.97 \\
\hline San Juan Juquila Mixes & 21.76 & 27.04 & 37.96 & 2.23 & 0.83 & 10.19 \\
\hline San Juan Mazatlán & 12.88 & 50.15 & 29.05 & 1.71 & 0.59 & 5.63 \\
\hline San Lucas Camotlán & 36.68 & 42.21 & 13.49 & 1.38 & 0.00 & 6.23 \\
\hline San Miguel Quetzaltepec & 5.46 & 50.08 & 35.39 & 1.20 & 0.08 & 7.78 \\
\hline San Pedro Ocotepec & 13.83 & 56.07 & 21.12 & 3.15 & 0.00 & 5.83 \\
\hline San Pedro y San Pablo Ayutla & 15.47 & 38.49 & 34.46 & 1.47 & 0.73 & 9.38 \\
\hline Santa María Alotepec & 7.70 & 25.63 & 58.57 & 1.06 & 0.40 & 6.64 \\
\hline Santa María Tepantlali & 15.03 & 43.75 & 23.99 & 4.90 & 1.69 & 10.64 \\
\hline Santa María Tlahuitoltepec & 17.01 & 12.52 & 54.24 & 6.99 & 1.09 & 8.15 \\
\hline Santiago Atitlán & 12.55 & 34.42 & 43.51 & 1.52 & 0.87 & 7.14 \\
\hline Santiago Ixcuintepec & 16.30 & 58.59 & 15.20 & 0.44 & 0.00 & 9.47 \\
\hline Santiago Zacatepec & 20.20 & 31.36 & 35.50 & 2.37 & 0.76 & 9.81 \\
\hline Santo Domingo Tepuxtepec & 14.21 & 53.15 & 20.93 & 3.36 & 1.41 & 6.94 \\
\hline Tamazulapam del Espíritu Santo & 13.41 & 14.81 & 63.01 & 2.92 & 0.93 & 4.91 \\
\hline Totontepec Villa de Morelos & 29.04 & 35.44 & 27.56 & 1.89 & 0.41 & 5.66 \\
\hline Porcentaje total en la región & 14.94 & 40.49 & 34.89 & 2.23 & 0.58 & 6.84 \\
\hline
\end{tabular}

Fuente: Instituto Federal Electoral, en http://pac.ife.org.mx

Nota: Los datos de esta tabla se refieren solamente a los votos emitidos, los cuales representan casi $40 \%$ de la lista nominal. Tampoco se tomaron en cuenta las casillas especiales. 


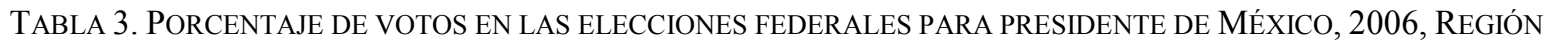
MIXE, OAXACA

\begin{tabular}{|c|c|c|c|c|c|c|}
\hline Nombre del municipio & $P A N$ & PRI & $P R D$ & Otros & No registrados & Nulos \\
\hline Asunción Cacalotepec & 11.64 & 40.49 & 41.31 & 1.15 & 0.49 & 4.92 \\
\hline Mixistlán de la Reforma & 7.02 & 68.40 & 21.07 & 0.46 & 0.31 & 2.75 \\
\hline San Juan Cotzocón & 15.66 & 39.82 & 39.95 & 1.12 & 0.42 & 3.03 \\
\hline San Juan Guichicovi & 3.05 & 44.50 & 49.86 & 0.49 & 0.18 & 1.92 \\
\hline San Juan Juquila Mixes & 21.83 & 27.38 & 39.04 & 1.95 & 0.74 & 9.07 \\
\hline San Juan Mazatlán & 12.45 & 50.38 & 30.06 & 1.60 & 1.12 & 4.39 \\
\hline San Lucas Camotlán & 38.06 & 39.79 & 15.57 & 0.69 & 0.00 & 5.88 \\
\hline San Miguel Quetzaltepec & 6.46 & 49.40 & 35.83 & 0.88 & 0.32 & 7.10 \\
\hline San Pedro Ocotepec & 13.84 & 56.80 & 21.00 & 2.15 & 0.00 & 6.21 \\
\hline San Pedro y San Pablo Ayutla & 16.18 & 38.10 & 32.66 & 1.96 & 1.09 & 10.01 \\
\hline Santa María Alotepec & 7.81 & 24.90 & 59.34 & 1.05 & 1.32 & 5.56 \\
\hline Santa María Tepantlali & 16.55 & 42.57 & 26.18 & 4.56 & 1.86 & 8.28 \\
\hline Santa María Tlahuitoltepec & 17.98 & 13.50 & 53.93 & 5.82 & 0.77 & 8.00 \\
\hline Santiago Atitlán & 13.15 & 35.13 & 41.81 & 1.51 & 0.65 & 7.76 \\
\hline Santiago Ixcuintepec & 15.64 & 60.35 & 14.54 & 0.66 & 0.00 & 8.81 \\
\hline Santiago Zacatepec & 21.71 & 30.07 & 35.39 & 1.78 & 1.10 & 9.97 \\
\hline Santo Domingo Tepuxtepec & 16.16 & 53.56 & 21.12 & 2.27 & 1.62 & 5.28 \\
\hline Tamazulapam del Espíritu Santo & 15.00 & 14.93 & 62.60 & 2.07 & 0.73 & 4.67 \\
\hline Totontepec Villa de Morelos & 22.91 & 36.17 & 33.31 & 1.55 & 0.82 & 5.24 \\
\hline Porcentaje total en la región & 15.42 & 40.32 & 35.50 & 1.77 & 0.71 & 6.25 \\
\hline
\end{tabular}

Fuente: Instituto Federal Electoral, en http://pac.ife.org.mx

Nota: Los datos de esta tabla se refieren solamente a los votos emitidos, los cuales representan casi $40 \%$ de la lista nominal. Tampoco se tomaron en cuenta las casillas especiales. 
Tabla 4. Porcentaje de votos en las elecciones para diputados locales, 2007, Región Mixe, OAXACA

\begin{tabular}{|c|c|c|c|c|c|c|c|c|}
\hline Nombre del municipio & $P A N$ & $A Q C$ & $P B T$ & $P U P$ & $P N A$ & $P A S D C$ & No registrados & Nulos \\
\hline Asunción Cacalotepec & 4.5 & 37.7 & 54.34 & 2.38 & 0.68 & 0.68 & 0.17 & 4.77 \\
\hline Mixistlán de la Reforma & 22.81 & 56.79 & 13.83 & 0.97 & 1.21 & 0.24 & 0 & 4.12 \\
\hline San Juan Cotzocón & 29.59 & 45.07 & 13.18 & 0.57 & 7.68 & 0.43 & 0.14 & 3.30 \\
\hline San Juan Guichicovi & 4.28 & 45.04 & 48.06 & 0.25 & 0.08 & 0.57 & 0 & 1.68 \\
\hline San Juan Juquila Mixes & 19.63 & 44.68 & 13.22 & 4.0 & 1.40 & 2.80 & 0.20 & 14.02 \\
\hline San Juan Mazatlán & 42.11 & 34.79 & 12.95 & 1.11 & 2.59 & 0.68 & 0.05 & 5.69 \\
\hline San Lucas Camotlán & 53.44 & 29.59 & 6.60 & 2.29 & 0 & 0.57 & 0.28 & 7.18 \\
\hline San Miguel Quetzaltepec & 24.93 & 52.27 & 14.13 & 1.20 & 0.46 & 0.46 & 0 & 6.51 \\
\hline San Pedro Ocotepec & 6.84 & 79.45 & 4.56 & 0.91 & 0.91 & 0.91 & 0 & 0.06 \\
\hline San Pedro y San Pablo Ayutla & 6.46 & 57.61 & 18.37 & 2.77 & 1.66 & 1.10 & 0.18 & 11.81 \\
\hline Santa María Alotepec & 15.56 & 37.31 & 34.75 & 1.70 & 1.06 & 0.85 & 0 & 8.74 \\
\hline Santa María Tepantlali & 15.32 & 56.82 & 12.53 & 6.68 & 1.39 & 1.67 & 0.55 & 5.01 \\
\hline Santa María Tlahuitoltepec & 7.94 & 16.82 & 63.43 & 2.21 & 0.70 & 1.63 & 0.11 & 7.12 \\
\hline Santiago Atitlán & 8.41 & 65.18 & 16.35 & 1.86 & 0.23 & 0.46 & 0 & 7.47 \\
\hline Santiago Ixcuintepec & 20.65 & 67.13 & 7.51 & 0.70 & 0.70 & 0 & 0 & 3.28 \\
\hline Santiago Zacatepec & 25.22 & 40.58 & 18.82 & 2.37 & 1.27 & 0.18 & 0 & 11.51 \\
\hline Santo Domingo Tepuxtepec & 5.93 & 72.71 & 10 & 3.22 & 0.84 & 0.50 & 0.16 & 6.61 \\
\hline Tamazulapam del Espíritu Santo & 10.10 & 26.30 & 47.49 & 2.74 & 1.66 & 3.82 & 0.29 & 7.55 \\
\hline Totontepec Villa de Morelos & 10.55 & 61.15 & 17.50 & 1.31 & 0.95 & 1.07 & 0.23 & 7.19 \\
\hline Porcentaje total en la región & 16.10 & 44.61 & 31.05 & 1.09 & 1.80 & 0.78 & .07 & 4.46 \\
\hline
\end{tabular}

Fuente: Instituto Estatal Electoral del Oaxaca, http://www.iee-oax.org.mx

$\mathrm{PAN}=$ Partido Acción Nacional $; \mathrm{AQC}=$ Alianza que Construye $; \mathrm{PBT}=$ Por el Bien de Todos; PUP $=$ Partido Unidad Popular; PNA = Partido Nueva Alianza; PASDC = Partido Alianza Social Demócrata y Campesina.

Nota: Los datos de esta tabla se refieren solamente a los votos emitidos, los cuales representan casi $40 \%$ de la lista nominal. Tampoco se tomaron en cuenta las casillas especiales. 


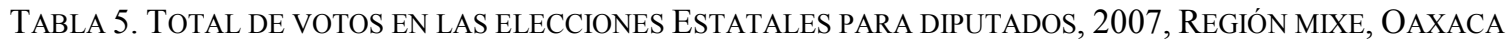

\begin{tabular}{|c|c|c|c|c|c|c|c|}
\hline Nombre del municipio & $P A N$ & $A Q C$ & $P B T$ & $\begin{array}{c}\text { Otros (PUP, PNA, } \\
\text { PASDC) }\end{array}$ & $\begin{array}{l}\text { No } \\
\text { registrados }\end{array}$ & Nulos & Total \\
\hline Asunción Cacalotepec & 25 & 192 & 319 & 22 & 1 & 28 & 587 \\
\hline Tamazulapam del Espíritu Santo & 103 & 268 & 484 & 84 & 3 & 77 & 1,019 \\
\hline Mixistlán de la Reforma & 94 & 234 & 57 & 10 & 0 & 17 & 412 \\
\hline San Juan Cotzocón & 1,228 & 1,870 & 547 & 361 & 6 & 137 & 4,149 \\
\hline San Juan Guichicovi & 487 & 5,119 & 5,463 & 104 & 0 & 192 & 11,365 \\
\hline San Juan Juquila Mixes & 98 & 223 & 66 & 41 & 1 & 70 & 499 \\
\hline San Juan Mazatlán & 1,479 & 1,222 & 455 & 154 & 2 & 200 & 3,512 \\
\hline San Lucas Camotlán & 186 & 103 & 23 & 10 & 1 & 25 & 348 \\
\hline San Miguel Quetzaltepec & 268 & 562 & 152 & 23 & 0 & 70 & 1,075 \\
\hline San Pedro Ocotepec & 15 & 174 & 10 & 6 & 0 & 14 & 219 \\
\hline San Pedro y San Pablo Ayutla & 70 & 624 & 199 & 60 & 2 & 128 & 1,083 \\
\hline Santa María Alotepec & 73 & 175 & 163 & 17 & 0 & 41 & 469 \\
\hline Santa María Tepantlali & 55 & 204 & 45 & 35 & 2 & 18 & 359 \\
\hline Santa María Tlahuitoltepec & 68 & 144 & 543 & 39 & 1 & 61 & 856 \\
\hline Santiago Atitlán & 36 & 279 & 70 & 11 & 0 & 32 & 428 \\
\hline Santiago Ixcuintepec & 88 & 286 & 32 & 6 & 0 & 14 & 426 \\
\hline Santiago Zacatepec & 138 & 222 & 103 & 21 & 0 & 63 & 547 \\
\hline Santo Domingo Tepuxtepec & 35 & 429 & 59 & 27 & 1 & 39 & 590 \\
\hline Totontepec Villa de Morelos & 88 & 510 & 146 & 28 & 2 & 60 & 834 \\
\hline Total de la región & 4,634 & 12,840 & 8,936 & 1,059 & 22 & 1,286 & 28,777 \\
\hline
\end{tabular}

Fuente: Instituto Estatal Electoral del Oaxaca, http://www.iee-oax.org.mx

PAN $=$ Partido Acción Nacional; AQC $=$ Alianza que Construye; $\mathrm{PBT}=$ Por el Bien de Todos; PUP = Partido Unidad Popular; PNA = Partido Nueva Alianza; PASDC $=$ Partido Alianza Social Demócrata y Campesina.

Nota: Los datos de esta tabla se refieren solamente a los votos emitidos, los cuales representan casi $40 \%$ de la lista nominal. Tampoco se tomaron en cuenta las casillas especiales.

En las elecciones para diputados del año 2006 ganó PRI en la región mixe con 41\% de votos; le siguió PRD con 34\% y PAN con apenas $15 \%$. En once de los diecinueve 
municipios mixes PRI obtuvo la victoria. En siete municipios ganó PRD. En un municipio, Camotlán, se presentó el difícil caso de empate entre PRI y PAN. Y en dos de los municipios donde ganó el PRD, Guichicovi y Zacatepec, lo hizo superando un apretado margen con PRI.

En las elecciones federales para senadores de 2006 ganó PRI en doce municipios con un promedio de $40.5 \%$ en la región, y PRD en siete, $34.9 \%$. La contienda estuvo muy cerrada entre ambos partidos en los municipios de Cacalotepec, Cotzocón y Zacatepec. El PAN apenas obtuvo $12 \%$ en el ámbito de la región, pero alcanzó el segundo lugar en Camotlán, Tlahuitoltepec, Ixcuintepec y Totontepec.

En las elecciones para presidente de la República de 2006 ganó PRI en diez municipios con $40 \%$ en la región, mientras que PRD en nueve con $35.5 \%$; y en Cotzocón y Cacalotepec estuvieron muy cerrados los comicios. Aunque PAN obtuvo tan sólo 15\% de las preferencias, consiguió ser la segunda fuerza política en Tamazulapam, Camotlán, Tlauitoltepec e Ixcuintepec.

Se puede decir que para el año 2006 los municipios simpatizantes del PRI fueron Mixistlán, Ocotepec e Ixcuintepec, cuyos porcentajes de voto en las tres elecciones federales mencionadas oscilan entre $56 \%$ y $68 \%$. Entretanto, los que simpatizaron más con PRD fueron Tamazulapam, Guichicovi, Alotepec y Tlahuitoltepec con un rango de 48\% a $63 \%$ de votos. El otro partido con posibilidades, PAN, sólo consiguió el municipio de Camotlán mediante 36 a 39\% de votos preferenciales. Otros partidos apenas alcanzaron de 1.8 a $2.4 \%$ de los votos en las tres elecciones.

En las elecciones estatales para diputados locales del año 2007 ganó Alianza que Construye - AQC; es decir, PRI con otras fuerzas políticas menores - en trece municipios con un promedio de $44.61 \%$ regional. En cuatro municipios ganó Por el Bien de Todos PBT - alianza PRD con otras fuerzas políticas menores- con 31.05\% de promedio regional. En los municipios de Alotepec y Guichicovi estuvo muy cerrada la votación entre ACQ y PBT, pero mientras que en Guichicovi esa competencia cerrada se mantiene desde las elecciones federales anteriores, en Alotepec se observó una drástica caída del PRD de aproximadamente 23 puntos porcentuales, la que lo colocó al nivel del PRI generando así su competencia. También llama la atención que para estos comicios los partidos minoritarios hayan aumentado la preferencia de los electores en 1.5 puntos porcentuales. 
Por lo tanto, aunque en la región mixe el voto por usos y costumbres constituye la mayoría de la fuerza política, lo es tan sólo para la elección de autoridades locales, así que la presencia de los partidos sigue teniendo plena vigencia para elegir diputados, senadores y presidente de la República. Las cifras de las votaciones federales del año 2006 y estatales de 2007 demuestran que en esta región se mantiene la propensión de votar por PRI como opción prioritaria. Esto se debe, en parte, a que no hay opción de voto por usos y costumbres para estas elecciones. También a que existe la idea muy arraigada de identificar al PRI con el gobierno, como si fueran la misma cosa, ya que por más de ocho décadas se ha mantenido en el poder del estado de Oaxaca y desde él ha llevado recursos y servicios a las comunidades y, aunque esta es la obligación de todo gobernante, en los pueblos mixes se cree que este partido es el que con mayor probabilidad «garantizará» que lleguen los recursos a las poblaciones. Además, ya que «siempre ha ganado» suponen que continuará haciéndolo y que por eso este partido sirve de puente para aquellos que tienen aspiraciones políticas fuera de su comunidad de origen.

No solo se dan estas condiciones, existen otras, más bien externas, que inciden de manera determinante para que PRI se mantenga como primera opción. Me refiero a las viejas prácticas y métodos que continúan ejerciendo los miembros de este partido y los funcionarios de gobierno simpatizantes para ganar las elecciones «por la buena»o «por la mala»: siguen ofreciendo recursos a cambio de votos y utilizando sus añejas formas de intervención en los asuntos políticos de los pueblos y comunidades mixes; regalan despensas, gorros, camisetas, dinero y promesas de recursos para las comunidades, pero también imponen a sus autoridades municipales, utilizando técnicas corruptas, y hasta balazos, como sucedió en Quetzaltepec durante el periodo 1998 a 2006, cuyos costos dañinos fueron muy altos para la comunidad, ya que además de haber quedado dividida desde entonces, llegaron a tales niveles de violencia que resultaron más de 40 lesionados y le costó la vida a una persona (La Jornada, 2002 y 2006).

Para los mixes que lo hacen, votar por el PRI significa «asegurar» la continuidad de lo que ya se conoce, conseguir recursos y la posibilidad de pactar ciertas complicidades de poder. Votar por el PRD, según lo que pude observar en campo, significa fundamentalmente sacar al PRI de la comunidad y trabajar para el pueblo. Votar por el PAN simboliza la alternativa para aquellos que se han decepcionado tanto del PRI como del 
PRD. En ninguno de los casos los ciudadanos tienen conocimiento previo y fundado del programa político del partido de su preferencia, pero esta situación no es exclusiva de la región mixe.

Sin embargo, no todo el saldo es negativo. Por el contrario, el reconocimiento de los usos y costumbres trajo como consecuencia una serie de beneficios para los pueblos mixes. En primer lugar, ha significado una revaloración de la dignidad étnica, toda vez que la máxima autoridad política, el Estado, validó una práctica local jurídica y cultural y la difundió ante un entorno social más amplio, como lo es el estado de Oaxaca y el propio país. Dicho reconocimiento, por venir de una autoridad externa y superior, devolvió valores positivos a las comunidades de origen contribuyendo así al soporte del sistema comunitario - aunque para algunos con la legalización de los usos y costumbres electorales se corrió el riesgo de promover la exacerbación de las prácticas autoritarias-. Pero este reforzamiento no ha sido posible en aquellos municipios cuya propia conflictividad y divisionismo lo han impedido. Son los casos de Quetzaltepec y Ayutla. El primero, como ya mencioné, quedó dividido después de la última intervención priísta en la comunidad; dicha separación se mantiene en pugna hasta hoy entre dos fuerzas principales: el grupo de los que se apoyan en el PRI y buscan continuar las elecciones por la vía de partidos políticos, y los que aspiran a continuar con la modalidad de usos y costumbres, apoyados en el respeto a las decisiones de la asamblea general comunitaria. En Ayutla sucede más o menos lo mismo pero, a diferencia de Quetzaltepec, aquí la asamblea general comunitaria sí se encuentra en franco deterioro, de ahí que la vida partidaria, específicamente priísta, sea mucho más fuerte.

Por su parte, Guichicovi puede considerarse caso único, pues allí se ha abandonado la práctica de la elección por usos y costumbres, y en consecuencia el tradicional sistema de cargos obligatorio y gratuito, así como el tequio y la aportación para las fiestas patronales; se ha desmantelado la asamblea general y la vida comunitaria para dar paso franco a la vida política partidaria. Sin embargo existen algunas reminiscencias, pues aún en el año 2003 se convocó a tequio para arreglar el camino, y aunque no todos acudieron porque no era obligatorio mucha gente sí participó.

En el resto de los municipios, el reconocimiento de los usos y costumbres para las elecciones de hecho ha significado el reforzamiento de su vida política local, especialmente en Alotepec, Atitlán, Cacalotepec, Tamazulapam, Tlahuitoltepec y Zacatepec, donde sus 
líderes e intelectuales han jugado un papel protagónico en la defensa de los valores comunitarios y la costumbre.

En otros municipios, dicho reconocimiento significó una alternativa para reencauzar la participación política a favor de la comunidad luego de haber sobrevivido a sus propias crisis políticas. Son los casos de Mixistlán y Zacatepec. El primero por haber subsistido a una ruptura comunitaria tan profunda que llevó a una de las partes a refundar la cabecera municipal, tierras más abajo, luego de haberse convertido a otra religión hace más de veinte años. El segundo por haber logrado la expulsión del último de los caciques, en 1998, acusado de robar al Instituto Mexicano del Café cuatro toneladas del grano en 1978; de daños a la salud por haberle encontrado plantíos de mariguana en sus terrenos, en 1986; de abuso de poder como presidente de la Unión de Productores de Café de la Confederación Nacional Campesina, a partir de 1986; por defraudar recursos destinados a la construcción de secadoras de café y obras de infraestructura no realizadas. Además, cuando fue alcalde, por medios ilegales abusó de la confianza de comuneros de distintas localidades productoras de café defraudándolos con sus cosechas; construyó dos casas en sus propiedades con materiales de la presidencia municipal; y destituyó ilegalmente a cuanto tesorero se intentó oponer a sus gestiones ilícitas.

En cambio, para Ocotepec la elección por usos y costumbres se sostiene con mucho esfuerzo pues no cuenta con el tamaño de población suficiente, carece de personal para cubrir los cargos del sistema, y esto provoca que cada vez sea más difícil cumplir en forma gratuita con él. Un indicador de este problema es que el número de votos emitidos en Ocotepec en 2007 fue el más bajo de la región: 219 votos, equivalentes a $0.76 \%$ del total regional (tabla 5).

Otro de los beneficios que trajo el reconocimiento de los usos y costumbres fue el incremento de poder en las comunidades que optaron por esta posibilidad. Los usos y costumbres han significado un recurso, una fuente más de poder que se suma al poder social comunitario, una bandera de lucha para contrarrestar el impacto de los partidos políticos en el ámbito local, especialmente en contra de PRI.

Pero el reconocimiento de los usos y costumbres trae consigo una paradoja, un contrasentido difícil de resolver. Los pueblos y comunidades indígenas que fueron beneficiados con esta reforma son sociedades marginadas, minoritarias y subordinadas que 
han sufrido los estragos del autoritarismo y que, a su vez, reproducen en su interior estas desigualdades: la discriminación, la exclusión y la imposición. Particularmente en lo que a elecciones se refiere estas desigualdades se aplican en la mayoría de los municipios contra las mujeres, los avecindados y los que no viven en las cabeceras municipales (Anaya s/f). Aunque en algunos municipios aceptan que las mujeres voten, las que lo hacen se atreven bajo una enorme presión masculina de la asamblea: no las escuchan cuando toman la palabra, no les toman en cuenta sus opiniones, a veces hasta hay burlas o las critican en voz baja. En cuanto a los avecindados en la región mixe, según la costumbre, no tienen derecho de voto en la asamblea si no han cumplido con sus obligaciones como cualquier ciudadano - pagar cuotas para fiesta, y cumplir con cargo y tequio.

El problema más severo que existe en la región de avecindados que no votan está en Cotzocón. Aquí no ha podido aplicarse la norma de la costumbre, es decir, obligar a los avecindados a cumplir con las responsabilidades para ser ciudadanos y tener derecho a voto. No se ha podido aplicar la norma porque los avecindados son invasores de tierras que se localizan en la parte más lejana del municipio, que es bastante grande por cierto, y donde no hay control de las autoridades municipales sino de las agencias, y estas no tienen el poder suficiente para obligar a que la norma se cumpla.

En el caso de los que no viven en las cabeceras municipales y que por esa razón no tienen derecho a voto existe realmente un conflicto, especialmente cuando las agencias crecen y demandan más participación. Pero, en efecto, en la región mixe los sistemas de gobierno son totalmente locales, sin importar que se trate de agencia o cabecera municipal. Los cargueros que cumplen con su servicio lo hacen porque viven en el lugar y tienen derecho a voto debido a que cumplen con su servicio. Pero ya que esta es la regla general, y se presenta vigente, se puede decir que los que no viven en la cabecera municipal no se quedan sin votar puesto que lo hacen en su localidad, lo que no hacen es votar para elegir a las autoridades del cabildo. Sin embargo, se han presentado casos en los que las autoridades de los cabildos han negociado la participación de las agencias en las funciones del cabildo para evitar confrontaciones, como en Tamazulapam y Tlahuitoltepec.

Un beneficio más que observo como resultado de este reconocimiento es para el Estado, no para los pueblos indígenas. Se trata de la economía en la administración de los procesos electorales, ya que la observación de estos procesos por parte de la autoridad 
competente es una responsabilidad muy laboriosa, pues para su cumplimiento el Instituto Estatal Electoral de Oaxaca lleva a cabo 117 diferentes acciones, cuando se trata de elecciones por partidos políticos, y tan sólo tres en el caso de usos y costumbres, que son:

1. «Aprobación del acuerdo por el que se precisan los municipios que renovarán concejales a los ayuntamientos bajo el régimen de normas de derecho consuetudinario y se ordena la publicación en el periodo oficial del catálogo general de los mismos — son responsables la Dirección de Elecciones por Usos y Costumbres, Dirección General y Consejo General, con fundamento legal en los artículos 71 fracción XVI y XXXIII, 110 y 114 del CIPEO, y se llevará a cabo el 13 de enero de 2007.

2. «Sesión especial del Consejo General en la que se declara la validez de la elección de concejales a los ayuntamientos de los municipios que se rigen por normas de derecho consuetudinario — son responsables la Dirección de Elecciones por Usos y Costumbres, Secretaría General, Dirección General y Consejo General, con fundamento legal en los artículos 71 fracción XXXIII, 73 inciso j), 78 inciso c), y 120 del CIPEO, y se llevará a cabo de agosto a diciembre de 2007.

3. «Integración de los expedientes de la elección de concejales a los ayuntamientos de los municipios que se rigen por normas de derecho consuetudinario validados por el consejo general y su remisión a la H. Cámara de Diputados para los efectos de ley — son responsables la Dirección de Elecciones por Usos y Costumbres, Secretaría General, Dirección General, con fundamento legal en los artículos 78 inciso c), 79 incisos d) y h), 121 y 122 del CIPEO, y se llevará a cabo de agosto a diciembre» (IEE s/f).

III

Al parecer, las elecciones por usos y costumbres estarán vigentes allí donde se practique la democracia directa (Méndez s/f), es decir, la participación cotidiana en los asuntos públicos, que es posible en gran medida gracias al tamaño de la población que permite controlar estas prácticas. Ya que la mayoría de las comunidades mixes cumplen con esta característica demográfica —excepto en Cotzocón, Guichicovi, Mazatlán, y muy pronto 
Tamazulapam y Tlahuitoltepec - la asamblea general comunitaria podrá continuar siendo el máximo órgano de gobierno. Todavía en la región la asamblea nombra al mayor número de cargueros para el sistema de gobierno, elige a 33.2\%; le siguen en importancia numérica los que voluntariamente se apuntan para cumplir un cargo, que representan 16\%; después los que son elegidos por sus homólogos, con 10.4\%; por los caracterizados, $7.4 \%$; por el cabildo, 7.2\%; por el alcalde, 6.9\%; y el mayor de vara, 3.5\% (Valdivia 2007).

Partiendo del hecho de que no puede haber una democracia plena sin un completo reconocimiento de las entidades indígenas como entidades políticas con derechos colectivos propios y diferenciados como bien lo han señalado varios autores (Aguilar s/f, Hernández s/f, López s/f, Montes s/f.) se requiere de una serie de acciones políticas más. Pero tratándose específicamente de materia electoral hay que señalar dos carencias fundamentales que se pueden solucionar al: 1) crear mecanismos para la resolución de las controversias electorales donde estén representados los pueblos indígenas; y 2) estipular que también por medio de los usos y costumbres pueden ser elegidos los diputados, senadores y gobernadores del estado de Oaxaca. ${ }^{2}$

El reconocimiento de los usos y costumbres electorales no es, desde mi punto de vista, un simple efecto de estrategias políticas del PRI para ganar legitimidad y preservar la gobernabilidad, aunque este partido se haya beneficiado en parte con ello, sino sobre todo significa una gran victoria en la batalla por la autonomía étnica, pese a sus contradicciones. Si bien aún se mantienen dos de las tres tendencias políticas en la región — dar preferentemente los votos al PRI y elegir a las autoridades locales conforme a su costumbre - , al reconocer la costumbre electoral la tercera «tendencia» desapareció, pues ahora los pueblos y comunidades ya no necesitan «negociar» con el gobierno estatal ni con PRI el voto a este partido, a cambio de la sobrevivencia de su costumbre e independencia electoral para la renovación de sus ayuntamientos.

Esta lucha por la autonomía ha tenido manifestaciones muy claras por parte de los pueblos indios, como bien lo señala Benjamín Maldonado (s/f): en la constante protección de sus territorios, en la defensa del municipio como entidad política, en la salvaguardia por mantener la asamblea como máximo órgano de gobierno, en el fortalecimiento de los consejos de ancianos, en la lucha por la gestión directa de los recursos, en la conservación de sus sistemas de elección por usos y costumbres, y en la recuperación del poder 
controlado por los caciques. Sin restar importancia al hecho de que el reconocimiento de los usos y costumbres forma parte del largo camino hacia la autonomía estoy de acuerdo en que para alcanzar el ejercicio de ésta se requiere también acuñar la autogestión, con el fin de que el diseño de las políticas de desarrollo —educación, salud, justicia— estén en manos de los propios beneficiarios.

Tepepan, Tlalpan, 7 de agosto de 2009, México, D. F. 


\section{BIBLIOGRAFÍA}

Aguilar Ortiz, Hugo, s/f, «Reglamentar los usos y costumbres», Servicios del Pueblo Mixe. En http://www.usosycostumbres.org/95.htm

Anaya Muñóz, Alejandro, s/f, «La legalización de los usos y costumbres electorales en Oaxaca: implicaciones éticas de una política de reconocimiento», Departamento de estudios Sociopolíticos y Jurídicos del Instituto Tecnológico de Estudios Superiores de Occidente. En http://www.usosycostumbres.org/Alejandro.htm

Hernández Díaz, Jorge, s/f, «Reflexionar para una reforma política-electoral incluyente». En http://www.usosycostumbres.org/Jorge.htm

IEE, Calendario General del proceso Electoral Ordinario 2007, Instituto Estatal Electoral de Oaxaca. En http://www.iee-oax.org.mx

—, s/f, «Procesos anteriores, 2006 y 2007», Instituto Estatal Electoral de Oaxaca. En http://www.iee-oax.org.mx

IFE, s/f, «Resultados de las elecciones federales 2006», Instituto Federal Electoral. En http://pac.ife.org.mx.

Jornada, La, 2006, «Elecciones en Quetzaltepec», núm. 10715, 31 de octubre. En http://www. noticias-oax.com.mx/articulos.php?id

«Quetzaltepec, un Acteal a la vista. Cuando el PRI mete su cuchara», 24 de febrero de 2002.

López Bárcenas, Francisco, s/f, «Derechos indígenas y derechos políticos en el estado de Oaxaca», Congreso Nacional Indígena. En http://www.usosycostumbres.org/ Francisco.htm 
Maldonado, Benjamín, 1998, «Obstáculos internos para la construcción de autonomías indias: una perspectiva desde Oaxaca». En Autonomías étnicas y Estados nacionales, coordinado por Miguel Alberto Bartolomé y Alicia Barabas. ConacultaINAH, México.

Méndez Lugo, Luis Adolfo, s/f, «Democracia directa, pluralismo político y diversidad». En http://www.usosycostumbres.org/Luisadolfo.htm

Montes, Adelfo Regino, s/f, «El nombramiento. Una reflexión teórica que contribuye a la construcción del pluralismo jurídico», Servicios del Pueblo Mixe. En http://www.usosycostumbres.org/Adelforegino.htm

Recondo, David, 1999, «Usos y costumbres y elecciones en Oaxaca. Los dilemas de la democracia representativa en una sociedad multicultural». En TRACE (Travaux et recherches sur les Amériques du centre), núm. 36, diciembre.

Valdivia Dounce, María Teresa, 2007, Catálogo de competencias jurídicas y normas en los sistemas de cargos ayuuk (mixes, 1998-2002). Instituto de investigaciones Antropológicas, UNAM, México. En http://132.248.110.3/cat-mixes/default.php.

2009, en prensa, Pueblos mixes: sus sistemas jurídicos, competencias y normas, Instituto de Investigaciones Antropológicas, UNAM, México. 


\section{Notas}

${ }^{1}$ Estudio sobre la normatividad jurídica en la región mixe con trabajos de campo de 1998 a 2009. Parte de los resultados de esta investigación están publicados en el Catálogo de competencias jurídicas y normas en los sistemas de cargos ayuuk (mixes, 1998-2002), IIA, UNAM, 2007. También en el libro, en prensa, Pueblos mixes: sus sistemas jurídicos, competencias y normas, IIA, UNAM, 2009.

${ }^{2}$ Francisco López Bárcenas tiene una propuesta para la elección de diputados locales: «Para lograrlo basta dividir cada uno de los 25 distritos electorales, digamos, en seis diputaciones, de manera que en promedio haya un diputado por cada cuatro municipios. Los cuatro municipios que se juntaran para tener un diputado tendrían que buscar la manera de que el cargo fuera rotativo; que uno de los municipios eligiera al diputado entre sus ciudadanos y en su asamblea, y al año siguiente o en el periodo siguiente fuera otro el municipio que lo hiciera, y así hasta volver a dar la vuelta. Esto permitiría tener diputados por usos y costumbres, electos por una asamblea comunitaria - la propia - directamente, sin urnas, boletas ni partidos — con sus compromisos asociados-, y por tanto esa misma asamblea podría destituirlos» (López s/f).

Fecha de recepción: 2 de abril de 2009.

Fecha de aceptación: 28 de julio de 2009. 